\title{
Pengaruh Kualitas Pelayanan Terhadap Kepuasan Pelanggan Di Unit Usaha Retail Kobantitar Mart
}

\author{
Reza Khairul Hadi
}

Universitas Pamulang. Email : rezakhairulhadi@gmail.com

\begin{abstract}
Tujuan dari penelitian ini adalah untuk mengetahui kualitas pelayanan Kobantitar Mart, mengetahui kepuasan konsumen Kobantitar Mart, dan mengetahui seberapa besar pengaruh kualitas pelayanan terhadap kepuasan konsumen Kobantitar Mart, Metode penelitian yang digunakan adalah metode kuantitatif, dan terdapat hubungan positif antara kualitas layanan dengan kepuasan pelanggan, dengan nilai regresi sebesar 0,687. Koefisien korelasi ( $r$ ) 0,583 menunjukkan bahwa terdapat hubungan yang cukup kuat antara kualitas pelayanan dengan kepuasan konsumen, nilai yang ditentukan $(\mathrm{Kd})$ 0,340. Pengujian hipotesis menggunakan uji statistik t hitung sehingga diperoleh $t$ hitung $>\mathrm{t}$ tabel $(7,112>1,660)$, yang dapat dikatakan signifikan .
\end{abstract}

Kata Kunci : Kualitas Pelayanan; Kepuasan Pelanggan

Keywords: The purpose of this study is to determine the quality of service Kobantitar Mart, to know Kobantitar Mart customer satisfaction, and to know how much influence the quality of service on customer satisfaction Kobantitar Mart. The research method used is quantitative methods, and there is a positive relationship between service quality and customer satisfaction, with a regression value of 0.687."The correlation coefficient ( $r$ ) 0,583 indicates that there is a strong enough relationship between service quality and customer satisfaction, the specified value (Kd) 0,340, Hypothesis testing uses the t-count statistical test in order to obtain $t$ count $t$ table $(7,112>1,660)$, which can be said to be significant".

Keywords: Service Quality; Customer Satisfaction 


\section{A. PENDAHULUAN}

"Dewasa ini diera globalisasi, produk atau jasa yang bersaing dalam satu pasar semakin banyak dan beragam akibat keterbukaan pasar, Sehingga terjadilah persaingan antara produsen untuk dapat memenuhi kebutuhan pelanggan serta memberikan kepuasan kepada pelanggan secara maksimal, Karena pada dasarnya tujuan dari suatu bisnis adalah untuk menciptakan rasa puas pada pelanggan, Kenyataan ini bisa dilihat, bahwa ada beberapa hal yang dapat memberikan kepuasan pelanggan yaitu nilai total pelanggan yang terdiri dari nilai produk, nilai pelayanan, nilai personal, nilai image atau citra, dan biaya total pelanggan yang terdiri dari biaya moneter, biaya waktu, biaya tenaga, dan biaya pikiran (Kotler; 2009:50)".

"Lingkungan global yang berubah semakin cepat saat ini menyebabkan setiap perusahaan, termasuk jasa mencoba mencari cara yang inovatif guna mencapai keunggulan kompetitif, meningkatkan loyalitas pelanggan, dan meningkatkan efesiensi tanpa mengorbankan kualitas pelayanan ( supranto, 2010), Moberrg menyebutkan beberapa bukti artikel yang menyatakan bahwa pemasar membuat perbedaan antara bisnis barang dan jasa, dan variasi strategi pemasarannya untuk memuaskan pelanggan".

"Menurut Kotler dalam Amstrong $(2001 ; 24)$ mengungkapkan bahwa Kualitas Pelayanan adalah upaya segala sesuatu yang dilakukan pihak tertentu baik individu maupun kelompok kepada pihak lain, Sedangkan menurut Fandy Tjiptono (2008;96), Kualitas Pelayanan adalah kualitas layanan yang ditentukan oleh kemampuan perusahaan dalam memenuhi kebutuhan dan keinginan pelanggan Pelanggan yang datang untuk berbelanja dapat terpenuhi keinginannya". Dari hal tersebut bahwa pelanggan tetap dan pelanggan baru akan sangat berkontribusi besar untuk kenaikan sales dan pelanggan akan lebih loyal dalam berbelanja dan pelanggan baru akan menjadi pelanggan tetap, sehingga asas visi dan misi perusahaan berjalan dengan baik. 
Tabel 1.1

Tabel Hasil Penjualan di unit usaha retail Kobantitar Mart pada tahun 2019

\begin{tabular}{|l|c|c|c|c|}
\hline \multicolumn{1}{|c|}{ Bulan } & $\begin{array}{c}\text { Target } \\
\text { Penjualan }\end{array}$ & $\begin{array}{c}\text { Realisasi } \\
\text { Pendapatan } \\
\text { Penjualan }\end{array}$ & $\begin{array}{c}\text { Presentasi } \\
\text { Hasil } \\
\text { Pencapaian }\end{array}$ & $\begin{array}{c}\text { Jumlah } \\
\text { pengunjung }\end{array}$ \\
\hline Januari & 200.000 .000 & 130.831 .400 & $65 \%$ & 5203 \\
\hline Februari & 200.000 .000 & 131.218 .100 & $66 \%$ & 4444 \\
\hline Maret & 200.000 .000 & 146.554 .050 & $73 \%$ & 5061 \\
\hline April & 200.000 .000 & 127.863 .250 & $64 \%$ & 4.091 \\
\hline Mei & 200.000 .000 & 120.128 .550 & $60 \%$ & 3.805 \\
\hline Juni & 200.000 .000 & 156.677 .200 & $78 \%$ & 971 \\
\hline Juli & 200.000 .000 & 138.779 .100 & $69 \%$ & 4.364 \\
\hline Agustus & 200.000 .000 & 130.597 .400 & $65 \%$ & 4.948 \\
\hline September & 200.000 .000 & 138.316 .750 & $69 \%$ & 4.948 \\
\hline Oktober & 200.000 .000 & 195.307 .600 & $98 \%$ & 8.177 \\
\hline November & 200.000 .000 & 146.133 .600 & $73 \%$ & 5.324 \\
\hline Desember & 200.000 .000 & 121.326 .200 & $61 \%$ & 3.519 \\
\hline
\end{tabular}

Sumber - Kepala Toko Kobantitar mart, (2020)

Dapat dilihat dari tabel diatas bahwa tingkat hasil realisasi pendapatan penjualan di unit usaha retail Kobantitar mart mengalami fluktuatif. Hal ini mengindikasikan bahwa penjualan di unit usaha retail kobantitar mart pada realisasi pendapatan penjualan terjadi fluktuatif (naik-turun), dan tidak selalu memenuhi target dalam penjualan yang telah ditentukan

Berdasarkan penjelasan latar belakang penelitian diatas dapat di simpukan: Kurangnya kecepatan waktu layanan yang diberikan karyawan unit usaha retail kobantitar mart. Pemahaman tentang kebutuhan pelanggan yang kurang dari karyawan di unit usaha retail kobantitar mart sehingga pelayanan yang diberikan belum maksimal. Penjualan di unit usaha retail Kobantitar mart selalu tidak mecapai target. Tingkat kebersihan pada rak gondola yang masih kurang bersih/kotor.

Adapun tujuan penelitian ini adalah sebagai berikut: untuk mengetahui kualitas pelayanan Kobantitar Mart, untuk megetahui kepuasan pelanggan Kobantitar Mart dan Seberapa besar pengaruh dari kualitas pelayan terhadap kepuasan pelanggan pada KObantitar Mart.

\section{B. KAJIAN LITERATUR}

\section{Kualitas Pelayanan}

"Kualitas layanan menurut Angelova dan Zekiri (2011:238) menyatakan bahwa perceived service quality is a global judgment, or attitude, relating to the superiority of the service, where as statisfactionis related to a spesific transaction.Kualitas pelayanan adalah penilaian global atau sikap berkaitan dengan keunggulan pada layanan, sedangkan kepuasan berkaitan dengan keunggulan tertentu,Pengertian kualitas pelayanan menurut $\mathrm{J}$, Supranto (2006:226) adalah sebuah kata yang bagi penyedia jasa merupakan sesuatu yang harus dikerjakan dengan baik". 


\section{Kepuasan Pelanggan}

"Menurut Kotler dalam Amstrong (2001:55) "Kepuasan pelanggan adalah ketiadaan perbedaan antara harapan yang dimiliki dan unjuk kerja yang senyatanya diterima. Apabila harapan tinggi, sementara unjuk kerjanya biasa-biasa saja, kepuasan tidak akan tercapai (sangat mungkin pelanggan akan merasa kecewa, Sebaliknya, apabila unjuk kerja melebihi yang diharapkan, kepuasan meningkat, Sedangkan menurut Supranto (2010:224) Kepuasan pelanggan ditentukan oleh kualitas barang/ jasa yang dikehendaki pelanggan sehingga jaminan kualita menjadi prioritas utama bagi setiap perusahaan, yang pada saat ini khususnya dijadikan sebagi tolak ukur keunggulan daya saing perusahaan".

\section{B. METODOLOGI PENELITIAN}

Bila dilihat dari sifat penelitiannya "penelitian ini merupakan penelitian bersifat Asosiatif kuantitatif, Metode asosiatif merupakan penelitian yang bertujuan untuk mengetahui pengaruh ataupun hubungan dua variabel atau lebih (Sugiyono, 2011;11) sedangkan penelitian kualitatif adalah penelitian yang data hasil penelitian lebih berkenaan dengan interpretasi terhadap data yang ditemukan di lapangan (Sugiyono, 2011;8)". Responden dalam penelitian ini adalah konsumen Kobantitar Mart sebanyak 100 orang. Data diuji menggunakan pengujian statistic kuantitatif.

\section{HASIL DAN PEMBAHASAN}

Tabel 2 : Deskripsi Jawaban Responden Terhadap Variabel (X)

\begin{tabular}{|c|c|c|c|c|c|c|c|c|c|c|}
\hline \multirow[b]{3}{*}{ Indikator } & \multirow[b]{3}{*}{ Kuesioner } & \multicolumn{5}{|c|}{ Jawaban Responden } & \multirow[b]{3}{*}{ Jml } & \multirow[b]{3}{*}{ Sampel } & \multirow[b]{3}{*}{$\begin{array}{l}\text { Rata- } \\
\text { rata }\end{array}$} & \multirow[b]{3}{*}{ Kriteria } \\
\hline & & 5 & 4 & 3 & 2 & 1 & & & & \\
\hline & & SB & $\mathrm{B}$ & KB & $\begin{array}{l}\mathrm{T} \\
\mathrm{B}\end{array}$ & $\begin{array}{l}\text { S } \\
T \\
B\end{array}$ & & & & \\
\hline \multirow{2}{*}{$\begin{array}{l}\text { Tangible } \\
\text { (Bukti fisik) }\end{array}$} & $\begin{array}{l}\text { 1. Lingkungan dan } \\
\text { area toilet selalu } \\
\text { terjaga kebersihannya }\end{array}$ & 42 & 45 & 13 & 0 & 0 & 429 & 100 & 4,29 & SB \\
\hline & $\begin{array}{l}\text { 2. Semua karyawan } \\
\text { berpenampilan rapih } \\
\text { sesuai SOP }\end{array}$ & 43 & 45 & 12 & 0 & 0 & 431 & 100 & 4,31 & SB \\
\hline \multicolumn{7}{|c|}{ Rata-rata Score Dimensi Tangible } & 860 & 200 & 4,30 & SB \\
\hline \multirow{2}{*}{$\begin{array}{l}\text { Keandalan } \\
\text { (reliability) }\end{array}$} & $\begin{array}{l}\text { 3. karyawan } \\
\text { memberikan } \\
\text { pelayanan yang baik } \\
\text { kepada pelanggan }\end{array}$ & 46 & 36 & 15 & 3 & 0 & 425 & 100 & 4,25 & SB \\
\hline & $\begin{array}{l}\text { 4. Apa yang diberikan } \\
\text { perusahaan tidak } \\
\text { mengelabui pelanggan }\end{array}$ & 14 & 60 & 18 & 8 & 0 & 380 & 100 & 3,8 & KB \\
\hline \multicolumn{7}{|c|}{ Rata-rata Score Dimensi Keandalan } & 792 & 200 & 3,96 & B \\
\hline
\end{tabular}




\begin{tabular}{|c|c|c|c|c|c|c|c|c|c|c|}
\hline \multirow[t]{2}{*}{$\begin{array}{l}\text { Daya } \\
\text { Tanggap } \\
\text { (Resposive } \\
\text { ness) }\end{array}$} & 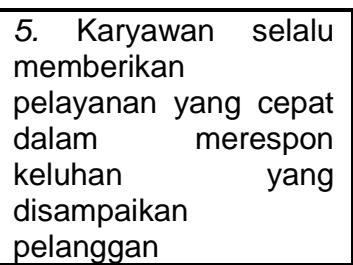 & 36 & 49 & 13 & 2 & 0 & 419 & 100 & 4,19 & B \\
\hline & $\begin{array}{lr}6 . & \text { Karyawan selalu } \\
\text { tanggap terhadap apa } \\
\text { yang } \\
\text { pelanggan }\end{array}$ & 28 & 53 & 17 & 2 & 0 & 407 & 100 & 4,07 & B \\
\hline \multicolumn{7}{|c|}{ Rata-rata Score Dimensi daya tanggap } & 826 & 200 & 4,13 & B \\
\hline \multirow{2}{*}{$\begin{array}{l}\text { Jaminan } \\
\text { (Assurance } \\
\text { ) }\end{array}$} & $\begin{array}{l}\text { 7. Kobantitar Mart } \\
\text { memberikan terbaik/ } \\
\text { pelayanan } \\
\text { Service Excellence }\end{array}$ & 41 & 41 & 17 & 1 & 0 & 422 & 100 & 4,22 & SB \\
\hline & $\begin{array}{l}\text { 8. Jaminan harga } \\
\text { produk sesuai dengan } \\
\text { harga yang tertera } \\
\text { pada rak display }\end{array}$ & 31 & 55 & 13 & 1 & 0 & 416 & 100 & 4,16 & B \\
\hline \multicolumn{7}{|c|}{ Rata-rata Score Dimensi jaminan } & 838 & 200 & 4,19 & B \\
\hline \multirow[b]{2}{*}{$\begin{array}{l}\text { Emapty } \\
\text { (Empaty) }\end{array}$} & $\begin{array}{lr}\text { 9. Dalam melayani } \\
\text { pelanggan karyawan } \\
\text { melayani dengan tulus } \\
\text { sepenuh hati }\end{array}$ & 17 & 71 & 8 & 4 & 0 & 401 & 100 & 4,01 & B \\
\hline & $\begin{array}{lr}10 & \text { Karyawan } \\
\text { menanggapi } & \text { dengan } \\
\text { baik dan memberikan } \\
\text { perhatian terhadap } \\
\text { kebutuhan d dan } \\
\text { keinginan pelanggan } \\
\end{array}$ & 16 & 62 & 19 & 3 & 0 & 391 & 100 & 3,91 & B \\
\hline \multicolumn{7}{|c|}{ Rata-rata Score Dimensi empaty } & 792 & 200 & 3,96 & B \\
\hline \multicolumn{7}{|c|}{ Total dan rata-rata skor variabel Kualitas pelayanan } & 4121 & 1200 & 4,12 & B \\
\hline
\end{tabular}

Sumber: Data Primer yang Diolah Berdasarkan Responden(2020)

Data dari keseluruhan penilaian berdasarkan keseluruhan indikator kualitas pelayanan, dapat simpulkan bahwa kualitas pelayanan yang ada pada konsumen kobantitar mart dikatakan Baik, hal ini dapat dilihat dari skor rata-rata variabel kualitas pelayanan sebesar 4121 dengan rata-rata 4,12 termasuk ada pada rentang skala interval $3.40-4.19$ dan memiliki kriteria Baik (B).Data

Tabel 3: Deskripsi Jawaban Responden Terhadap Variabel (Y) 
ISSN No. (PRINI) 2598-0823, (ONLINE) 2598-2893

\begin{tabular}{|c|c|c|c|c|c|c|c|c|c|c|}
\hline \multirow{3}{*}{ Indikator } & \multirow{3}{*}{ Kuisioner } & \multicolumn{5}{|c|}{ Jawaban Responden } & \multirow{3}{*}{$\begin{array}{l}\text { Jumla } \\
\mathrm{h}\end{array}$} & \multirow{3}{*}{$\begin{array}{l}\text { Samp } \\
\text { el }\end{array}$} & \multirow{3}{*}{$\begin{array}{l}\text { Rata - } \\
\text { Rata }\end{array}$} & \multirow{3}{*}{ Ket } \\
\hline & & 5 & 4 & 3 & 2 & 1 & & & & \\
\hline & & SB & B & KB & TB & $\begin{array}{l}\mathrm{T} \\
\mathrm{B}\end{array}$ & & & & \\
\hline \multirow[t]{2}{*}{$\begin{array}{l}\text { Dapat } \\
\text { Memenuhi } \\
\text { Harapan }\end{array}$} & $\begin{array}{l}\text { Perusahaan selalu } \\
\text { memenuhi keinginan } \\
\text { pelanggan untuk } \\
\text { mendapatkan produk yang } \\
\text { berkualitas dan dengan } \\
\text { harga yang terjangkau }\end{array}$ & 27 & 51 & 20 & 2 & 0 & 403 & 100 & 4,03 & B \\
\hline & $\begin{array}{l}\text { 2. Perusahaan selalu } \\
\text { memberikan potongan } \\
\text { harga ketika ada promosi } \\
\text { produk }\end{array}$ & 27 & 50 & 21 & 2 & 0 & 402 & 100 & 4,02 & B \\
\hline $\begin{array}{l}\text { Rata-rata } \\
\text { Score } \\
\text { Dimensi } \\
\text { Dapat } \\
\text { Memenuhi } \\
\text { Harapan }\end{array}$ & 805 & 200 & 4,03 & B & & & & & & \\
\hline \multirow{2}{*}{$\begin{array}{l}\text { Dapat } \\
\text { Memenuhi } \\
\text { Kebutuhan }\end{array}$} & $\begin{array}{l}\text { 3. Produk kebutuhan } \\
\text { pokok yang ditawarkan } \\
\text { kepada pelanggan selalu } \\
\text { dalam kondisi baik }\end{array}$ & 27 & 52 & 20 & 1 & 0 & 405 & 100 & 4,05 & B \\
\hline & $\begin{array}{l}\text { 4. Pemenuhan kebutuhan } \\
\text { pelanggan selalu menjadi } \\
\text { prioritas utama bagi } \\
\text { perusahaan }\end{array}$ & 41 & 41 & 17 & 1 & 0 & 422 & 100 & 4,22 & SB \\
\hline \multicolumn{7}{|c|}{ Rata-rata Score Dimensi Dapat Memenuhi Kebutuhan } & 827 & 200 & 4,14 & $\mathrm{~B}$ \\
\hline
\end{tabular}

Jurnal Pemasaran Kompetitif, Vol. 04, No. 3 / Juni 2021 


\begin{tabular}{|c|c|c|c|c|c|c|c|c|c|c|}
\hline \multirow{2}{*}{$\begin{array}{l}\text { Sedia } \\
\text { Untuk } \\
\text { Merekome } \\
\text { ndasikan }\end{array}$} & $\begin{array}{l}5 . \text { Kepuasan yang saya } \\
\text { dapatkan dalam } \\
\text { berbelanja sehingga saya } \\
\text { merekomendasikan } \\
\text { kepada orang lain untuk } \\
\text { berbelanja di Kobantitar } \\
\text { Mart }\end{array}$ & 33 & 39 & 22 & 6 & 0 & 399 & 100 & 3,99 & B \\
\hline & $\begin{array}{l}\text { 6. Kebutuhan yang tidak } \\
\text { ada ditempat lain, } \\
\text { sehingga saya } \\
\text { merekomendasikan ke } \\
\text { orang lain untuk belanja ke } \\
\text { kobantitar mart }\end{array}$ & 29 & 48 & 21 & 2 & 0 & 404 & 100 & 4,04 & $\mathrm{~B}$ \\
\hline \multicolumn{7}{|c|}{ Rata-rata Score Dimensi Sedia Untuk Merekomendasikan } & 803 & 200 & 4,02 & $\mathrm{~B}$ \\
\hline \multirow{2}{*}{$\begin{array}{l}\text { Kurang } \\
\text { Memperhat } \\
\text { ikan Merek } \\
\text { Lain }\end{array}$} & $\begin{array}{l}\text { 7. Harga jual produk di } \\
\text { toko kobantitar lebih } \\
\text { terjangkau dibanding kan } \\
\text { ditempat lain }\end{array}$ & 22 & 59 & 19 & 0 & 0 & 403 & 100 & 4,03 & B \\
\hline & $\begin{array}{l}\text { 8. Pelayanan yang baik } \\
\text { membuat saya tidak } \\
\text { berbelanja ditempat lain }\end{array}$ & 19 & 57 & 18 & 6 & 0 & 389 & 100 & 3,89 & $\mathrm{~B}$ \\
\hline \multicolumn{7}{|c|}{ Rata-rata Score Dimensi Kurang Memperhatikan Merek Lain } & 792 & 200 & 3,96 & $\mathrm{~B}$ \\
\hline \multirow{2}{*}{$\begin{array}{l}\text { Menawarka } \\
\mathrm{n} \quad \text { Ide } \\
\text { Kepada } \\
\text { Perusahaa } \\
\text { n }\end{array}$} & $\begin{array}{l}\text { 9. Sebagai Pelanggan } \\
\text { saya memberikan } \\
\text { masukan yang positif } \\
\text { kepada pihak perusahaan }\end{array}$ & 40 & 54 & 5 & 1 & 0 & 433 & 100 & 4,33 & SB \\
\hline & 10. Saya memberikan ide & 27 & 52 & 17 & 4 & 0 & 402 & 100 & 4,02 & $\mathrm{~B}$ \\
\hline
\end{tabular}


ISSN No. (PRINT) 2598-0823, (ONLINE) 2598-2893

\begin{tabular}{|l|l|l|l|l|l|l|l|}
\hline & $\begin{array}{l}\text { dalam pengembangan } \\
\text { inovasi } \\
\text { perusahaan }\end{array}$ & & & & & & \\
\hline \\
Rata-rata Score Dimensi Menawarkan Ide Kepada Perusahaan
\end{tabular}

Sumber: Data Primer yang Diolah Berdasarkan Responden(2020)

Data di atas dari keseluruhan penilaian berdasarkan keseluruhan indikator kepuasan pelanggan, dapat simpulkan bahwa kepuasan pelanggan kobantitar mart dalam kondisi Baik (B), hal ini dapat dilihat dari skor rata-rata variabel kepuasan pelanggan sebesar 4061 dengan rata-rata 4.06 termasuk ada pada rentang skala interval 3.40 - 4.19 dan memiliki kriteria Baik (B), disebabkan terdapat pengaruh kualitas pelayanan terhadap kepuasan pelanggan yang diakukan oleh konsumen kobantitar mart.

Berdasarkan hasil pengumpulan data primer dan sekunder jumlah survei yang didistribusikan kepada para peserta adalah 100, dan semuanya telah dikembalikan.

\section{Pengujian Instrumen}

\section{a. Uji validasi variabel}

Tabel 4 Hasil Uji Validitas Variabel X dan Y

\begin{tabular}{|c|l|l|l|}
\hline Item Kuesioner X & Nilai $r$ hitung & Nilai $r$ tabel & Keputusan \\
\hline X1 & 0,517 & 0,165 & Valid \\
\hline X2 & 0,451 & 0,165 & Valid \\
\hline X3 & 0,584 & 0,165 & Valid \\
\hline X4 & 0,407 & 0,165 & Valid \\
\hline X5 & 0,536 & 0,165 & Valid \\
\hline X6 & 0,563 & 0,165 & Valid \\
\hline X7 & 0,484 & 0,165 & Valid \\
\hline X8 & 0,337 & 0,165 & Valid \\
\hline X9 & 0,351 & 0,165 & Valid \\
\hline X10 & 0,449 & 0,165 & Valid \\
\hline
\end{tabular}


ISSN NO. (PRINT) 2598-0823, (ONLINE) 2598-2893

\begin{tabular}{|c|l|l|l|}
$\begin{array}{c}\text { Item Kuesioner } \\
Y\end{array}$ & Nilai $r$ hitung & Nilai $r$ tabel & Keputusan \\
\hline Y1 & 0,740 & 0,165 & Valid \\
\hline Y2 & 0,549 & 0,165 & Valid \\
\hline Y3 & 0,547 & 0,165 & Valid \\
\hline Y4 & 0,517 & 0,165 & Valid \\
\hline Y5 & 0,781 & 0,165 & Valid \\
\hline Y6 & 0,392 & 0,165 & Valid \\
\hline Y7 & 0,503 & 0,165 & Valid \\
\hline Y8 & 0,635 & 0,165 & Valid \\
\hline Y9 & 0,344 & 0,165 & Valid \\
\hline Y10 & 0,293 & 0,165 & Valid \\
\hline
\end{tabular}

Sumber: Data Primer yang diolah (2020)

Variabel diatas angka 0,165 atau $\left(r_{\text {hitung }}>r_{\text {tabel), }}\right.$ maka semua item dinyatakan valid.

3. Uji Reliabilitas

Tabel 5 Hasil Uji Reliabilitas

\begin{tabular}{|l|l|l|l|l|}
\hline No & Item Kuesioner & $\begin{array}{l}\text { Nilai Cronbach } \\
\text { Alpha }\end{array}$ & Nilai Pembanding & Hasil \\
\hline 1 & Kualitas Pelayanan & 0,701 & 0,60 & Reliabel \\
\hline 3 & Kepuasan Pelanggan & 0,729 & 0,60 & Reliabel \\
\hline
\end{tabular}

Sumber: Data diolah 2019

Nilai cronbach alpha pada variabel kualitas pelayanan sebesar 0,701 , variabel kepuasan pelanggan 0,729 yang masing-masing nilai $>0,60$.

\section{Analisis Koefisien Korelasi}

Tabel 6 Hasil Uji Koefisien Korelasi

\begin{tabular}{|l|l|l|l|l|}
\hline Model & $R$ & $R$ Square & $\begin{array}{l}\text { Adjusted R } \\
\text { Square }\end{array}$ & $\begin{array}{l}\text { Std. Error of the } \\
\text { Estimate }\end{array}$ \\
\hline 1 & $583^{\text {a }}$ &, 340 &, 334 & 3,25562 \\
\hline
\end{tabular}

Sumber: Data diolah 2019

Diperoleh koefisien korelasin 0,583 dengan interpretasi Cukup Kuat. Artinya variabel kualitas pelayanan mempunyai hubungan yang Cukup Kuat terhadap kepuasan pelanggan. 


\section{Analisis Koefisien Determinasi (R-square)}

Tabel 7 Hasil Uji Koefisien Determinasi

\begin{tabular}{|l|l|l|l|l|}
\hline Model & $R$ & R Square & $\begin{array}{l}\text { Adjusted R } \\
\text { Square }\end{array}$ & $\begin{array}{l}\text { Std. Error of the } \\
\text { Estimate }\end{array}$ \\
\hline 1 &, $583^{a}$ &, 340 &, 334 & 3,25562 \\
\hline
\end{tabular}

\section{Sumber: Data diolah 2019}

Analisis koefisien determinasi 0.340 , maka dapat disimpulkan bahwa $(\mathrm{X}),(\mathrm{Y})$ sebesar $34 \%$ sedangkan $66 \%$ dipengaruhi oleh faktor lain

\section{Analisis Regresi Linier Sederhana}

Tabel 8 Hasil Uji Regresi Linier sederhana

\begin{tabular}{|l|l|l|l|l|l|}
\hline \multirow{2}{*}{ Model } & \multicolumn{2}{|l|}{$\begin{array}{l}\text { Unstandardized } \\
\text { Coefficients }\end{array}$} & $\begin{array}{l}\text { Standardize } \\
\text { d } \\
\text { Coefficients }\end{array}$ & & \\
\cline { 2 - 5 } & $\mathrm{B}$ & Std. Error & Beta & $\mathrm{t}$ & Sig. \\
\hline $1 \quad \begin{array}{l}\text { (Constant) } \\
\begin{array}{l}\text { Total Kualitas } \\
\text { Pelayanan }\end{array}\end{array}$ & 12,149 & 3,993 & & 3,043 &, 003 \\
\hline
\end{tabular}

Sumber: Data diolah 2019

Berdasarkan hasil perhitungan regresi linier sederhana persamaan regresinya yaitu:

$Y=12,149+0,687 X$

Persamaan di atas dapat dijelaskan :

1) Nilai konstanta 12,149 kualitas pelayanan tidak dipertimbangkan atau ( $X=0)$ maka kualitas pelayanan bernilai hanya mencapai sebesar $12,149 \%$.

2) Nilai koefisien regresi 0,687 kualiatas pelayanan berpengaruh positif terhadap kepuasan pelanggan. Jika kualitas pelayanan ditingkatkan maka kepuasan pelanggan pada Kobantitar Mart meningkat

\section{Pengujian Hipotesis / Uji t}

Tabel 9 Hasil Uji Hipotesis 
ISSN No. (PRINT) 2598-0823, (ONLINE) 2598-2893

\begin{tabular}{|c|c|c|c|c|c|c|c|}
\hline \multicolumn{8}{|c|}{ Coefficients $^{\mathrm{a}}$} \\
\hline \multirow[b]{2}{*}{ Mode } & & & \multicolumn{2}{|c|}{ Unstandardized Coefficients } & \begin{tabular}{|l|} 
Standardized \\
Coefficients
\end{tabular} & \multirow[b]{2}{*}{$\mathrm{t}$} & \multirow[b]{2}{*}{ Sig. } \\
\hline & & & $\mathrm{B}$ & Std. Error & Beta & & \\
\hline$\overline{1}$ & (Constant) & & 12,149 & 3,993 & & 3,043 &, 003 \\
\hline & $\begin{array}{l}\text { Total } \\
\text { Pelayanan }\end{array}$ & Kualitas &, 687 & &, 583 & 7,112 &, 000 \\
\hline
\end{tabular}

Sumber : Sumber : Data diolah 2019

Dari tabel 9 diperoleh nilai thitung $>$ ttabel atau $(7,112>1,660)$ hal ini juga diperkuat dengan nilai signifikansi $0,000<0,05$.

Hasil dari uji statistik menunjukkan bahwa ada hubungan yang cukup kuat antara variabel kualitas pelayanan terhadap kepuasan pelanggan hal ini dibuktikan oleh hasil uji koefisien determinasi sebesar 0,583. Dengan kontribusi sebesar 34\% yang ditunjukkan oleh hasil uji koefisien determinasi, serta terdapat pengaruh yang positif dari hasil uji regresi linier sederhana dengan nilai $Y=12,149+0,687 X$. dan hasil uji hipotesis t menunjukkan adanya pengaruh yang signifikan dengan nilai t hitung $>$ t tabel yaitu 7,112 >1,660.

\section{E. KESIMPULAN}

1. Kualitas Pelayanan yang diterapkan pada Kobantiar Mart, dari 100 responden dengan 10 pernyataan dengan rata - rata skor 4,12 dikategorikan BAIK. Atas deskripsi jawaban responden terhadap variabel $(X)$

2. Kepuasan pelanggan pada Kobantiar Mart mendapat respon yang beragam dari 100 responden dengan 10 pernyataan dengan rata - rata skor 4.06 dikategorikan BAIK. Atas deskripsi jawaban responden terhadap variabel $(Y)$

3. Terdapat pengaruh positif antara Kualitas Pelayanan terhadap Kepuasan pelanggan dengan nilai regresi $Y=12,149+0,687 X$. Nilai koefisien korelasi $(r) 0,583$ artinya kualitas pelayanan memiliki hubungan yang CUKUP KUAT terhadap kepuasan pelanggan dan nilai determinasi (Kd) 0.340 atau $34 \%$ sedangkan sisanya sebesar $66 \%$ dipengaruhi oleh faktor lain. Pengujian hipotesis menggunakan uji statistik t hitung diperoleh thitung $>$ ttabel $(7,112>1,660$

Disarankan kepada manajemen Kobantitar mart agar dapat meningkatkan pelayanannya khususnya dalam hal empathy dan kehandalan dalam memberikan pelayanan agar tercapai kepuasan bagi konsumennya

\section{DAFTAR PUSTAKA}


Angelova, B and Zekiri. J. 2011. Gale Education, Religion and Humanities Lite Package.Word Count: 7696.

Darmadi, \& Setiawan, R. (2020). Analisis Implementasi Global Vision Melalui Straregi Pemasaran Perusahaan Roti Maulana Bakery Yang Berimplikasi Pada Daya Saing.

Darmadi, D. (2020). Pengaruh Lingkungan Kerja dan Disiplin Kerja Terhadap Kinerja Karyawan Pada Indomaret Cabang Kelapa Dua Gading Serpong Kabupaten Tangerang. JIMF (Jurnal IImiah Manajemen Forkamma), 3(3), 240-247"

J, Supranto. 2006. Pengukuran Tingkat Kepuasan Pelanggan Untuk Menaikkan Pangsa Pasar. Jakarta: Rineka Cipta.

Jurnal Ekonomi Efektif, 2(2), 316-325".

Kotler dan Keller. 2009. Manajemen Pemasaran. Edisi ke 13. Jakarta: Erlangga.

Kotler, Amstrong. 2001. Prinsip-prinsip pemasaran. Edisi kedua belas. Jilid 1. Jakarta: Erlangga.

Lesmana, R. (2019). Analisis Strategi Bersaing PT Dwi Perkasa Mobiltama Pamulang untuk Meningkatkan Penjualan. JIMF (Jurnal IImiah Manajemen Forkamma), 3(1)

Lesmana, R., Habiyah, W., \& Nabila, N. I. (2020). Peran Kepuasan Wisatawan Terhadap Loyalitas Wisatawan Pada Objek Wisata Kepulauan Seribu Jakarta. JIMF (Jurnal IImiah Manajemen Forkamma), 3(2).

Lesmana, R., Sunardi, N., Hastono, H., \& Widodo, A. S. (2021). Perceived Quality Membentuk Customer Loyalty via Brand Equity pada Pengguna Smartphone Merek Xiaomi di Tangerang Selatan. Jurnal Pemasaran Kompetitif, 4(2), 157-167

Lesmana, R., Sutarman, A., \& Sunardi, N. Building A Customer Loyalty Through Service Quality Mediated by Customer Satisfaction.

Stjiptono, Fandy,2008, Strategi Pemasaran, Edisi 3, andi: Yograyakarta.

Sugiyono. 2011. Metode Penelitian Kuantitatif dan Kualitatif dan $R$ \& D. Bandung: CV Alfabeta

Sunardi, N., \& Lesmana, R. (2020). Konsep Icepower (Wiramadu) sebagai Solusi Wirausaha menuju Desa Sejahtra Mandiri (DMS) pada Masa Pandemi Covid19. JIMF (Jurnal IImiah Manajemen Forkamma), 4(1).

Supranto. 2010. Pengukuran Tingkat Kepuasan Pelanggan. Bogor: Yudhistira.

Terry, George dan Leslie W. Rue. 2010. Dasar-Dasar Manajemen. Cetakan Kesebelas. Jakarta: PT Bumi Aksara 